\title{
Article \\ Effects of Different Freezing Methods on Water Distribution, Microstructure and Protein Properties of Cuttlefish during the Frozen Storage
}

\author{
Ying Lv ${ }^{1}$, Yuanming Chu ${ }^{1}$, Pengcheng Zhou ${ }^{1}$, Jun Mei ${ }^{1,2,3,4}$ and Jing Xie ${ }^{1,2,3,4, *(\mathbb{D}}$ \\ 1 College of Food Science and Technology, Shanghai Ocean University, Shanghai 201306, China; \\ 15900328167@163.com (Y.L.); cym072096@163.com (Y.C.); 13122327916@163.com (P.Z.); \\ jmei@shou.edu.cn (J.M.) \\ 2 Shanghai Engineering Research Center of Aquatic Product Processing \& Preservation, \\ Shanghai Ocean University, Shanghai 201306, China \\ 3 National Experimental Teaching Demonstration Center for Food Science and Engineering, \\ Shanghai Ocean University, Shanghai 201306, China \\ 4 Collaborative Innovation Center of Seafood Deep Processing, Ministry of Education, Dalian 116034, China \\ * Correspondence: jxie@shou.edu.cn; Tel.: +86-021-61900351
}

check for updates

Citation: Lv, Y.; Chu, Y.; Zhou, P.; Mei, J.; Xie, J. Effects of Different Freezing Methods on Water Distribution, Microstructure and Protein Properties of Cuttlefish during the Frozen Storage. Appl. Sci. 2021, 11, 6866. https://doi.org/ 10.3390/app11156866

Academic Editor: Alessandra Durazzo

Received: 21 June 2021

Accepted: 25 July 2021

Published: 26 July 2021

Publisher's Note: MDPI stays neutral with regard to jurisdictional claims in published maps and institutional affiliations.

Copyright: (c) 2021 by the authors Licensee MDPI, Basel, Switzerland. This article is an open access article distributed under the terms and conditions of the Creative Commons Attribution (CC BY) license (https:// creativecommons.org/licenses/by/ $4.0 /)$.

\begin{abstract}
To study the effect of different freezing methods on the quality changes of cuttlefish during the frozen storage of cuttlefish, fresh cuttlefish was treated with six freezing methods (refrigerator direct-freezing, saline solution impregnation freezing, flat freezing, tunnel type continuous freezing, air-blast freezing and liquid nitrogen freezing) and then stored at $-18{ }^{\circ} \mathrm{C}$ for 90 days. The time to pass the maximum ice crystal generation zone for the above six freezing methods in this experiment was $165.5,67.5,34.5,21.8,20.4$ and $1.5 \mathrm{~min}$, respectively. In this study, water retention (thawing loss rate, centrifugal loss rate, and cooking loss), $\mathrm{pH}$, malondialdehyde content, TVB-N value, and sulfhydryl content were measured to evaluate the quality after thawing. Protein secondary structure was measured by attenuated total reflection infrared spectroscopy (ATR-FTIR), water migration was determined by low-field NMR, and muscle microstructure was observed by scanning electron microscopy. The results showed that among the six freezing methods, liquid nitrogen freezing took the shortest time to pass through the maximum ice crystal generation zone. And it had the highest water retention, the lowest TVB-N content, the highest sulfhydryl content and the least irregular curling of protein secondary structure after 90 days of frozen storage. However, liquid nitrogen freezing can cause cracks and breakage in cuttlefish due to cryogenic fracture caused by ultra-low temperature, which affects its sensory evaluation. Although the freezing speed of flat freezing is faster than refrigerator direct-freezing and saline solution impregnation freezing, the muscle is extruded and deformed during the freezing process, and the damage is more serious, and the frozen storage quality is the worst. The comprehensive analysis results showed that the freezing speed of air-blast freezing was faster and the quality of cuttlefish in the freezing process was better, which was the more recommended freezing method, and this study provided some theoretical basis for the selection of freezing method in the actual production of cuttlefish.
\end{abstract}

Keywords: cuttlefish; freezing method; liquid nitrogen freezing; frozen storage; air-blast freezing

\section{Introduction}

Cuttlefish belongs to the Mollusca, Cephalopoda and Sepiida, and they live mainly in shallow waters along tropical and temperate coasts. Cuttlefish has typical high protein, low fat characteristics, and is rich in minerals and a variety of essential amino acids. Its meat is crisp, tender, tasty and rich in nutrients. It is very popular among consumers.

Fresh cuttlefish moisture content is high, the tissue protease activity is strong, the fish is easy to die after capture, easy to rot and deteriorate, not easy to store, the preservation of freshness is difficult [1]. Therefore, proper handling and preservation methods are needed 
to increase the shelf life of cuttlefish. At present, freezing is still the most important form of fish circulation process, but also to improve the comprehensive utilization of aquatic products and value-added important way.

Freezing preservation is a preservation method that first uses cooling equipment to lower the temperature of the center of the aquatic products, freeze most of the water inside, and then freeze the aquatic products at $-18^{\circ} \mathrm{C}$ and below. The degree of impact on the quality of aquatic products is different. Common freezing methods are mainly air freezing method, flat freezing method, tunnel continuous freezing method, dipping freezing method, liquid nitrogen flash freezing, etc. It was found that the freezing quality of fish products is related to the freezing method and freezing rate. The freezing rate affects the size and uniformity of ice crystals. Quick freezing produces fine and uniform extracellular and intracellular ice crystals, which does little damage to the food structure. However, slow freezing will produce large and irregular extracellular ice crystals, leading to the destruction of muscle structure and reducing the sensory acceptance of food. In addition, the size of ice crystals can increase with the extension of freezing time [2]. Research showed that freezing can inhibit the reproduction of microorganisms, inhibit enzyme activity, slow fat oxidation, protein denaturation, which can make the freshness of fish for several months or even more than a year. Nonetheless, quality deterioration still inevitably occurs during freezing and frozen storage, such as texture softening, fluid losses, color changes, and flavor deterioration. However, different freezing methods, depending on their processes and freezing rates, can have different effects on the degree of protein and fat oxidation, muscle tissue morphology, color and texture, and water loss of aquatic products, etc. [3,4]. Boonsumrej et al. [5] evaluated the quality changes of tiger shrimp (Penaeus monodon) frozen using air-blast and cryogenic freezing. The results indicated that freezing the shrimps under the air-blast freezer at the air velocity of $6 \mathrm{~m} / \mathrm{s}$ had the least freezing loss and same cutting force as the fresh shrimps. Goncalves et al. [6] concluded that the use of liquid nitrogen freezing improved process yield when compared to the use of spiral freezer. There is hardly any available information about the effects of freezing methods on the integrity, physicochemical, and sensory properties of cuttlefish. Research by Xu et al. showed that compared with static air freezing and air blast freezing, the quality of catfish fillets frozen by liquid nitrogen immersion is better. There have been reports in the literature on the effects of different freezing methods on the quality of other aquatic products, but there is hardly any available information about the effects of freezing methods on the integrity, physicochemical and sensory properties of cuttlefish.

The aim of this study was to investigate the effects of six different freezing methods on the quality of cuttlefish, and to explore the most suitable freezing method to maintain the quality of cuttlefish by evaluating the changes of physicochemical properties and microscopic results during the freezing process, and to provide theoretical reference and technical support for the preservation of cuttlefish.

\section{Materials and Methods}

\subsection{Sample Preparation}

An average weight of $1.0 \mathrm{~kg}$ of fresh cuttlefish was purchased from the local market (Luchao Port, Pudong New Area, Shanghai, China) in October, covered with crushed ice and packed in a foam box, and delivered to the Aquatic Products Preservation Laboratory of Shanghai Ocean University within $20 \mathrm{~min}$ for temporary storage in a $4{ }^{\circ} \mathrm{C}$ refrigerator.

\subsection{Freezing Treatment}

The impurities on the surface of the fish were cleaned with flowing cooling water, weighed, and then thermocouples were inserted into the center of the cuttlefish (tunnel continuous freezing method using wireless temperature sensors) and packed in self-sealing bags for putting into refrigerator direct-freezing, $29.3 \% \mathrm{CaCl}_{2}$ saline solution impregnation freezing, flat freezing, tunnel type continuous freezing, air-blast freezing and liquid nitrogen freezing. 34970A multi-channel thermocouples (Agilent, Santa Clara, CA, USA) were 
used to measure the temperature change during freezing. The temperature measuring end of the multi-channel thermocouples were inserted from the head of the cuttlefish to the center of the cuttlefish body and when the center temperature reached $-18^{\circ} \mathrm{C}$, the samples were immediately taken out and put into $-18{ }^{\circ} \mathrm{C}$ refrigerator for freezing, and the relevant indexes were measured by running thawing at a sampling point every 30 days during the storage period of 90 days.

\subsection{Thawing Loss}

Thawing loss was determined according to the protocol as described by CohenZinder et al. [7] The mass of the cuttlefish before freezing was recorded as M1. After thawing, the surface of the cuttlefish was dried with kitchen paper, weighed again and the mass was recorded as M2. Thawing loss was calculated according to the following equation.

$$
\text { Thawing loss }(\%)=\frac{\mathrm{M} 2}{\mathrm{M} 1} \times 100 \%
$$

\subsection{Cooking Loss}

The cooking loss was measured according to Li et al. [8]. Cuttlefish samples of size $2 \mathrm{~cm} \times 2 \mathrm{~cm} \times 2 \mathrm{~cm}$ was taken and the actual weight (M3) was recorded, these samples were packed and sealed in a boilable bag and cooked in an $85^{\circ} \mathrm{C}$ water bath for $20 \mathrm{~min}$. After cooking, the cuttlefish pieces were removed and cooled to room temperature. The surface was wiped with filter paper and the recorded weight (M4), cooking loss was recorded using the following equation.

$$
\text { Cooking loss }(\%)=\frac{\mathrm{M} 3-\mathrm{M} 4}{\mathrm{M} 3} \times 100 \%
$$

\subsection{Centrifugal Loss}

Remove $1 \mathrm{~cm} \times 1 \mathrm{~cm} \times 1 \mathrm{~cm}$ of cuttlefish meat and record the weight as M5. Wrap with filter paper and place in a centrifuge tube. Centrifuge at $5000 \mathrm{r} / \mathrm{min}$ for $10 \mathrm{~min}$ at $4{ }^{\circ} \mathrm{C}$. At the end of centrifugation, remove it and weigh it and record the weight of cuttlefish meat M6. The water retention capacity was calculated as follows [9].

$$
\text { Centrifugal loss }(\%)=\frac{\mathrm{M}_{5}-\mathrm{M}_{6}}{\mathrm{M}_{5}} \times 100 \%
$$

\section{6. $\mathrm{PH}$}

The cuttlefish samples were weighed $2 \mathrm{~g}$, added with $18 \mathrm{~mL}$ of distilled water and homogenized mechanically, then centrifuged at $5000 \mathrm{r} / \mathrm{min}$ for $3 \mathrm{~min}$, and the $\mathrm{pH}$ value of the supernatant was measured by $\mathrm{pH}$ meter (Sartorius, Gottingen, Germany). Each group was repeated three times and the average value was taken.

\subsection{Low-Field Nuclear Magnetic Resonance (LF-NMR)}

With a slight modification referring to Wang's method. [10]. The thawed cuttlefish meat was made into a sample of $3 \mathrm{~cm} \times 3 \mathrm{~cm} \times 1 \mathrm{~cm}$ and placed in the measurement channel of an LF-NMR analyzer (MesoMR23-060H.I, Niumag Corporation, Shanghai, China). A Carr-Purcell-Meiboom-Gill (CPMG) sequence was used with $\mathrm{T}_{2}$ measurements: $\mathrm{SW}=100 \mathrm{kHz}, \mathrm{RG} 1=20, \mathrm{P} 1=19.00 \mu \mathrm{s}, \mathrm{DRG} 1=3, \mathrm{TD}=400,066, \mathrm{PRG}=1, \mathrm{TW}=2000 \mathrm{~ms}$, $\mathrm{NS}=4, \mathrm{P} 2=37.00 \mu \mathrm{s}, \mathrm{TE}=0.500$, The CPMG exponential decay profile was obtained followed by iterative inversion to obtain the transverse relaxation time $\mathrm{T}_{2}$ profile. Imaging was performed by the PQ001 benchtop pulsed MRI analyzer, followed by uniform mapping and pseudo-coloring of the proton density map to obtain the MRI map. 


\subsection{Determination of Microstructure by SEM}

The method of Syamaladevi [11] was followed with slight modifications. The cuttings of cuttlefish frozen by different freezing methods, $5 \mathrm{~cm}$ long and about $5 \mathrm{~mm}$ in diameter, were dried in a freeze-dryer for $72 \mathrm{~h}$. The freeze-dryer was pre-cooled in advance and the plate temperature was set at $-10{ }^{\circ} \mathrm{C}$ with a vacuum of $20 \mathrm{~Pa}$. After freeze-drying, the samples were cut into $5 \mathrm{~mm} \times 5 \mathrm{~mm} \times 3 \mathrm{~mm}$ thin slices, placed on gold-guided adhesive tape, sprayed with gold, and scanned by electron microscopy at $5.0 \mathrm{kv}$ voltage. The surface structure state of the cuttlefish samples was observed.

\subsection{Myofibrillar Protein Extraction}

The myofibrillar protein was extracted in line with the method of Li et al. [12]. $2 \mathrm{~g}$ of minced cuttlefish was accurately weighed into a $50 \mathrm{~mL}$ centrifuge tube, buffered with $20 \mathrm{~mL}$ of buffer $(20 \mathrm{mmol} / \mathrm{L}$ Tris-maleate, $0.05 \mathrm{~mol} / \mathrm{L} \mathrm{KCl}, \mathrm{pH}=7.0)$, homogenized, and the precipitate was taken by centrifugation at 12,000 r/min for $12 \mathrm{~min}$, and the process was repeated twice. The last precipitate was added into $20 \mathrm{~mL}$ buffer B $(20 \mathrm{mmol} / \mathrm{L}$ Trismaleate, $0.6 \mathrm{~mol} / \mathrm{L} \mathrm{KCl}, \mathrm{pH}=7.0$ ), homogenized, extracted at $4{ }^{\circ} \mathrm{C}$ for $3 \mathrm{~h}$, centrifuged at $10,000 \mathrm{r} / \mathrm{min}$ for $15 \mathrm{~min}$, and the supernatant was myofibrillar protein solution.

\subsection{Determination of Sulfhydryl (SH) Group Content}

Myofibrillar protein solution was added to the reagents sequentially according to the method of the kit, mixed well and left for $10 \mathrm{~min}$ at room temperature, zeroed with distilled water, and the absorbance of each tube was measured by YS6010 spectrophotometer (3 nh, Shenzhen, China) at $412 \mathrm{~nm}$, and the average value was obtained by repeating each group three times.

\subsection{Total Volatile Base Nitrogen (TVB-N)}

Determination of TVB-N by the method of $\mathrm{Yu}$ [13]. Method for determination of TVB-N. $5 \mathrm{~g}$ of cuttlefish muscle was weighed and an automated Kjeltec 8400 nitrogen analyzer (FOSS, Foss, Denmark) was used to determine TVB-N values.

\subsection{Fourier Infrared Spectroscopy}

The secondary structure of cuttlefish proteins was studied using a Spotlight 400 FT-IR spectrometer (PerkinElmer, Waltham, MA, USA). Referring to the method of Kobayashi et al. [14]. samples were scanned 64 times from 600 to $4000 \mathrm{~cm}^{-1}$ with a resolution of $1 \mathrm{~cm}^{-1}$. Spectra were collected at room temperature $\left(20-22{ }^{\circ} \mathrm{C}\right)$ using approximately $0.5 \mathrm{~g}$ of lyophilized MP placed on the surface of attenuated total reflectance (ATR) crystals. The obtained spectra were deconvoluted and curve-fitted using Peak Fit EXE professional software to analyze protein secondary structure changes. Three measurements from duplicate samples were collected to obtain an average of the spectral data.

\subsection{Lipid Oxidation}

Weigh $2.0 \mathrm{~g}$ of cuttlefish meat and homogenize in a centrifuge tube using $18 \mathrm{~mL}$ of physiological saline and centrifuge at $8000 \mathrm{r} / \mathrm{min}$ for $15 \mathrm{~min}$. The supernatant was taken to measure the amount of malondialdehyde (MDA). The amount of MDA was quantified by thiobarbituric acid reaction method (TBA) using commercial kit A003-1 (Nanjing Jiancheng Institute of Biological Engineering, Nanjing, China) [15]. After using the kit, it was measured at $532 \mathrm{~nm}$ using an enzyme-labeled instrument (Thermo scientific, Shanghai, China).

\subsection{Sensory Evaluation}

The Quality Index Method (QIM) was extracted according to Meral et al. with a slight modification [16]. The cuttlefish was cleaned by removing the head, skin and guts, and then sensory scored by 10 (6 males and 4 females, aged between 22 and 30 years) trained professional panelists. The cuttlefish were scored at each sampling time for color, odor, 
apperance. 10 points indicated the best quality and lower scores indicated poorer quality. The sensory laboratory room environment was controlled at around $20^{\circ} \mathrm{C}$ and all panelists were evaluated independently without interaction.

\subsection{Statistical Analysis}

One-way analysis of variance (ANOVA) and Duncan's multiple range test were used to determine significant differences between means using SPSS 22.0. Analysis of variance (ANOVA) and Duncan's multiple range test $(p=0.05)$ were performed. And Origin 2021 software was used for plotting.

\section{Results and Discussion}

\subsection{Freezing Time}

From Table 1, it can be seen that the time required to freeze cuttlefish from the freezing starting point at $4{ }^{\circ} \mathrm{C}$ to the freezing end point at $-18{ }^{\circ} \mathrm{C}$ and the time to pass through the maximum ice crystal generation zone was: $\mathrm{RF}>\mathrm{SF}>\mathrm{FF}>\mathrm{TF}>\mathrm{BF}>\mathrm{LF}$. It was found that comparing brine immersion freezing with freezing in a refrigerator, it was found that brine immersion freezing greatly reduced the total freezing time and the time to pass through the maximum ice crystal generation zone, because the thermal conductivity of $\mathrm{CaCl}_{2}$ was significantly better than that of air. When brine immersion freezing, the cuttlefish was in direct contact with the freezing medium through the bag, and heat transfer was fast, which allowed for more rapid cooling, because the cold exchange between the frozen product and the freezing medium is more rapid when the liquid is frozen quickly, which increases the molecular heat exchange and intramolecular potential energy. However, in order to isolate the contact between the freezing liquid and the cuttlefish, sealed packaging was used, which reduces the heat transfer rate of the freezing process to a certain extent. The wind speed inside the spiral quick-freezing machine was $6.5 \mathrm{~m} / \mathrm{s}$. Also, since the spiral quick-freezing conveyor belt was mesh-like, there was air flow on both sides of the top and bottom, while the air-blast quick-freezing machine was forced convection heat exchange on the top side, and the contact with the shelf was heat conduction. Flat freezing was to press the cuttlefish placed inside the fish tray between two heat-conducting plates, and freeze the fish by heat transfer of heat conduction. Liquid nitrogen freezing enables samples to pass quickly through the maximum ice crystal generation zone, which had also been confirmed in related studies.

Table 1. Comparison of freezing time of cuttlefish under different freezing methods.

\begin{tabular}{ccc}
\hline Freezing Methods & $\begin{array}{c}\text { Time to Pass the Maximum } \\
\text { Ice Crystal Generation Zone } \\
\left.\text { of } \mathbf{- 1} \text { to }-\mathbf{5}{ }^{\circ} \mathbf{C} \text { ( } \mathbf{m i n}\right)\end{array}$ & $\begin{array}{c}\text { Total Freezing Time } \\
\left.\mathbf{( 4}{ }^{\circ} \mathbf{C} \sim-\mathbf{1 8}{ }^{\circ} \mathbf{C}\right)(\mathbf{m i n})\end{array}$ \\
\hline RF (Refrigerator direct-freezing) & $165.52 \pm 20.51 \mathrm{a}$ & $635.87 \pm 57.2 \mathrm{a}$ \\
SF (29.3\% Saline solution impregnation freezing) & $67.5 \pm 11.20 \mathrm{~b}$ & $365.44 \pm 33.4 \mathrm{~b}$ \\
FF (Flat freezing) & $34.5 \pm 3.58 \mathrm{c}$ & $295.53 \pm 31.5 \mathrm{c}$ \\
TF (Tunnel type continuous freezing) & $21.8 \pm 2.77 \mathrm{c}$ & $187.14 \pm 10.55 \mathrm{~d}$ \\
BF (Air-blast freezing) & $20.4 \pm 1.89 \mathrm{c}$ & $155.0 \pm 9.43 \mathrm{~d}$ \\
LF (Liquid nitrogen freezing) & $1.5 \pm 0.22 \mathrm{~d}$ & $6.52 \pm 0.65 \mathrm{e}$ \\
\hline
\end{tabular}

The letters "a-e" indicate significant differences $(p<0.05)$.

\subsection{Water Retention}

The water retention of aquatic products affects their texture, appearance and freezing stability, and is an important and significant parameter to reflect the quality of aquatic products. The reduction of water retention capacity of frozen aquatic products may be due to two reasons: first, the mechanical damage of muscle tissue structure by ice crystals and internal stresses, causing the expansion of cell gaps or cell membrane rupture, resulting in the outflow of extracellular fluid and part of the internal fluid. Second, the change of protein structure makes its water retention capacity decrease, and the water melted by ice crystals 
cannot be reunited with protein molecules and separated out [17]. The effect of thawing loss during freezing of cuttlefish treated with different freezing methods was shown in Figure 1A. The thawing loss of cuttlefish treated with the six freezing methods gradually increased with increasing freezing time. In the whole storage process, the thawing loss of flat frozen cuttlefish was higher than the other five groups in the whole storage cycle, which was due to the fact that the heat-conducting plate in the flat freezing would form a squeezing pressure on the cuttlefish, and the overall structure of the cuttlefish received a serious deformation from the external damage, and the damage to the muscle tissue was greater.

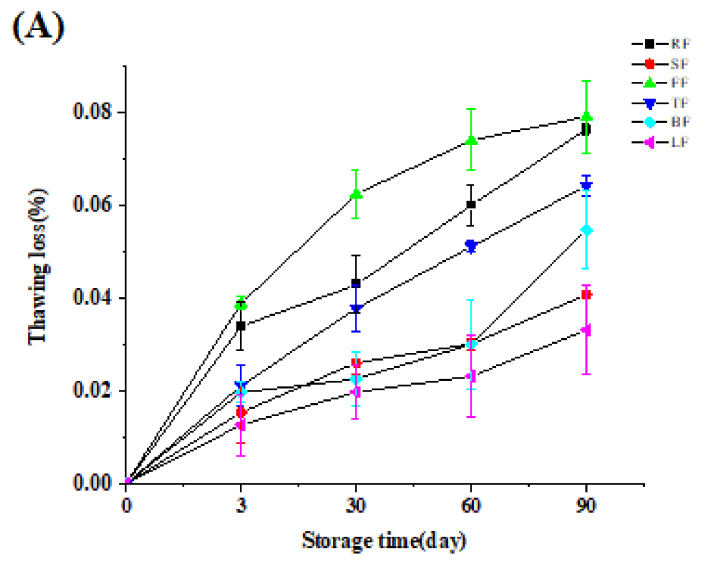

(B)

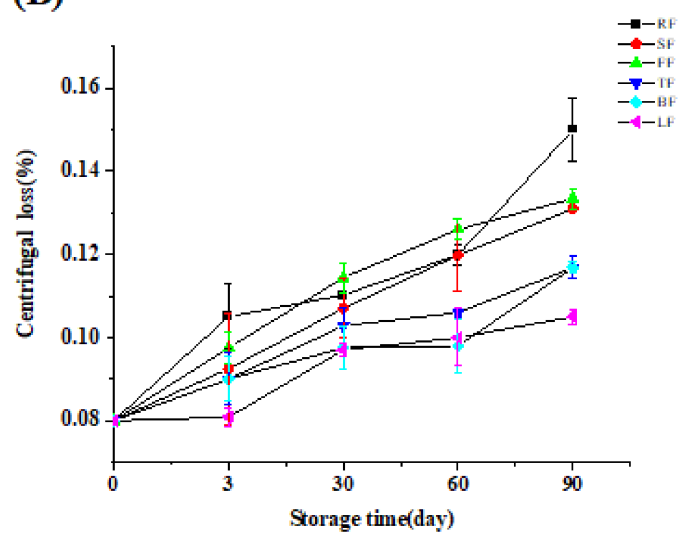

(C)

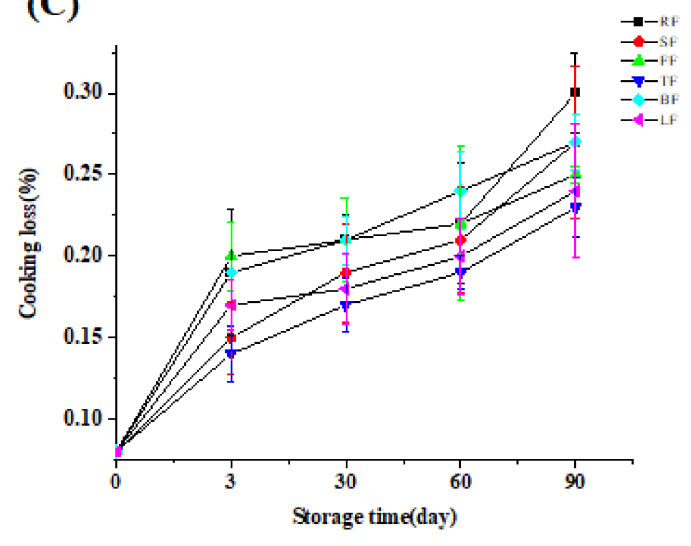

Figure 1. Change in water retention of cuttlefish during storage at $-18{ }^{\circ} \mathrm{C}$ by different freezing methods. Thawing loss (A). Centrifugal loss (B). Cooking loss (C). Error bars show standard deviation.

Cooking loss and centrifugal loss are all indicators to evaluate the water holding capacity of meat products [18]. The water-holding capacity of meat directly affects the juiciness, nutrient content, tenderness and color of meat and other edible qualities, and can reflect to some extent the degree of protein denaturation by freezing. The steaming loss and centrifugal loss of fresh cuttlefish were $8.02 \%$ and $12.10 \%$, respectively. Figure $1 B, C$ show the effect of freezing method on the centrifugal loss and cooking loss rate of cuttlefish during frozen storage, respectively. With the increase of storage time, the steaming loss rate and centrifugal loss rate of all six freezing methods showed an increasing trend. The cooking loss rate and centrifugal loss rate of cuttlefish treated by freezing in refrigerator direct-freezing were the largest, while the water holding capacity of the TF, BF and LF groups with fast freezing speed was higher, probably because the slow freezing speed formed larger irregular ice crystals, which damaged the tissue structure of cuttlefish and led to a decrease in the water holding capacity of the fish. Queiroga et al. [19] also showed 
that the cooking losses of shrimp Parapeneus vannamei were significantly reduced after fast freezing, which is similar to the results of the present experiment. This could be due to the formation of larger ice crystals in the shrimp flesh due to slow freezing, which caused a greater degree of damage to the muscle tissue structure, resulting in a weaker water-holding capacity of the shrimp.

\section{3. $\mathrm{PH}$}

The $\mathrm{pH}$ values between 6.8 and 7 are generally proposed as acceptable limits for fish. Although $\mathrm{pH}$ is not a suitable index on its own, the values of samples can be useful as additional criteria in quality control measures when used in conjunction with other quality parameters. Increased $\mathrm{pH}$ values may be caused by degradation of products such as ammonia and trimethylamine, typical end products derived from endogenous enzyme activities and bacterial spoilage [20]. As shown in Figure 2, the $\mathrm{pH}$ of fresh cuttlefish was 6.95, which was close to 7.0. With the extension of freezing time, the $\mathrm{pH}$ of cuttlefish meat showed a trend of decreasing and then increasing. The $\mathrm{pH}$ of cuttlefish reached the lowest value on day 30, and the $\mathrm{pH}$ values of $\mathrm{RF}, \mathrm{SF}, \mathrm{FF}, \mathrm{TF}, \mathrm{BF}$ and $\mathrm{LF}$ groups were 6.34, 6.38, $6.32,6.39,6.46$ and 6.61 , respectively. The faster the rate of freezing, the slower the $\mathrm{pH}$ drop. In the middle and late stages of freezing, various enzymes and microorganisms in the flesh of cuttlefish slowly decomposed the protein and nitrogenous compounds in the flesh into alkaline nitrogenous substances, resulting in a rising trend of $\mathrm{pH}$ in the fillets, and the $\mathrm{pH}$ in the LF group increased most slowly, followed by the TF and BF groups. It may be due to the fact that low temperature can inhibit the activity of enzymes and slow down the multiplication of microorganisms, and the fastest freezing speed of liquid nitrogen quick-freezing is more favorable to inhibit the activity of enzymes and the growth of microorganisms in the fish tissue, thus slowing down the glycogen decomposition and protein degradation in the organism. The change of muscle $\mathrm{pH}$ value of aquatic products is closely related to its freshness, so the $\mathrm{pH}$ value of muscle during storage of aquatic products can also be used as an index to evaluate its freshness.

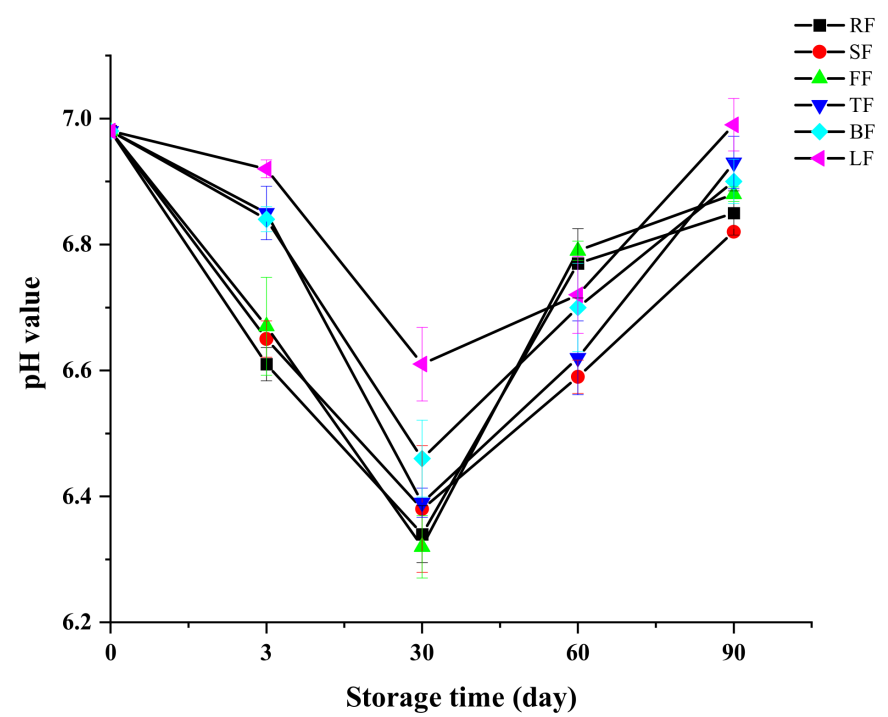

Figure 2. Change in $\mathrm{pH}$ value of cuttlefish during storage at $-18{ }^{\circ} \mathrm{C}$ by different freezing methods. Error bars show standard deviation.

\subsection{Transverse Relaxation Time $\left(T_{2}\right)$ of LF-NMR}

The distribution and mobility of water molecules are considered as relevant parameters for changes in fish products during freezing, freezing and thawing. Low-field nuclear magnetic resonance (LF-NMR) uses the principle of energy exchange between nuclei at a fixed magnetic distance $(1 \mathrm{H})$ to analyze sample composition. $\mathrm{T}_{2}$ transverse relaxation times measured by low-frequency NMR have been shown to detect the presence of sev- 
eral water groups in the muscle tissue of aquatic products [21,22]. As can be seen from the Figure 3A, two forms of water were detected from fresh cuttlefish meat: one is the fastest-emerging peak of the relaxation component $\mathrm{T}_{21}$ representing bound water, which represents water tightly bound to macromolecules in the range of 1.80 2.01\%, distributed in the sarcoplasmic, sarcolemma and myogenic fiber protein The other was the major relaxation component, $\mathrm{T}_{22}$, which represents water that is not readily mobile, ranging from 98.00 98.19\%, and represents water that was encapsulated or immobilized in highly organized structures, such as water adsorbed in protein tertiary and quaternary structures, or located within the space of high-density myogenic fibers, including actin and myosin filaments [23]. In cuttlefish meat stored after freezing, in addition to the two types of water mentioned above, another component with the slowest peak emergence, $\mathrm{T}_{23}$, was detected, this relaxation component was the least abundant, between $0.02 \%$ and $0.4 \%$, it is free water distributed outside the structure of the myogenic fibrin network, in this component was not detected in fresh samples, this may be due to the growth of ice crystals after freezing which destroyed some cells and increased the content of free water. The variation in composition and structure of different fish species led to the variation in relaxation time. As shown in Figure 3F, the content of free water in cuttlefish under the six groups of freezing methods showed a significant increasing trend throughout the storage cycle. Refrigerator direct-freezing had the slowest freezing rate, generated larger ice crystals, grew ice crystals in later storage, caused severe mechanical damage to cells, and had the highest free water content at 90 day. Although liquid nitrogen freezing had the fastest freezing rate, the lack of free water content was not the lowest, because the generated low temperature fracture phenomenon would cause some damage to the muscle tissue, which would convert some water to free water. Tunnel continuous freezing and air-blast freezing had the lowest content on day 90, which may be due to having a faster freezing rate and maintaining the morphological integrity of the cuttlefish during the freezing process.

Magnetic resonance imaging (MRI) is a technique that can obtain MRI images of water and fat in muscle, which can visualize the distribution and migration of water during the processing of fish products. Usually, the higher the brightness value and the higher the proton density, the more it tends to be red, indicating a higher water content in that part of the fish, and the color of MRI of fresh cuttlefish meat is close to red. It can be seen from Figure 4 that the color of MRI maps of fish flesh in LF group was the reddest and the proton density was the largest at the $3 \mathrm{~d}$, while the color of RF group had tended to be yellow, and some yellow-blue color had appeared in the edge part, and the difference between the brightness of proton density-weighted image of air-blast freezing treatment and spiral freezing was not obvious. The color of MRI maps of RF group and FF group was less uniform, which indicated that the freezing method was different, and the difference in the moisture distribution states also differed, probably because the freezer freezing rate was too slow, generating larger ice crystals and more damage to muscle tissues, and the water loss in cells was more serious after thawing, while the plate freezing would have an external force on the cuttlefish, causing a greater degree of mechanical damage to the muscle. At the 90th day, the moisture content of cuttlefish after liquid nitrogen freezing was the highest, and the brightness distribution was more uniform, and the brightness of RF, SF and FF groups was weaker, indicating that the cuttlefish had more water loss after freezing and storage. 


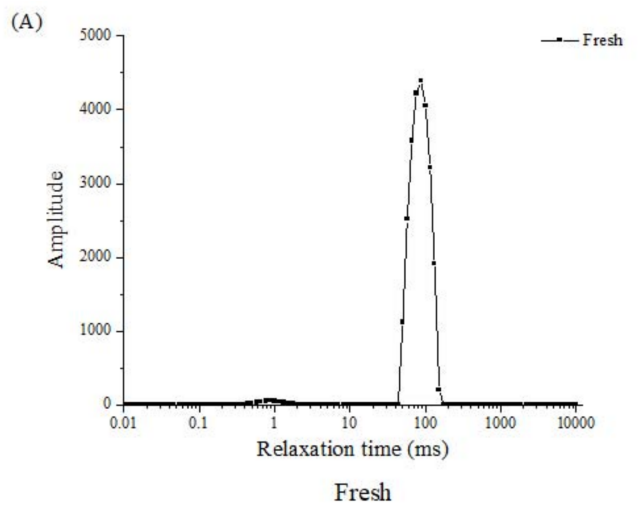

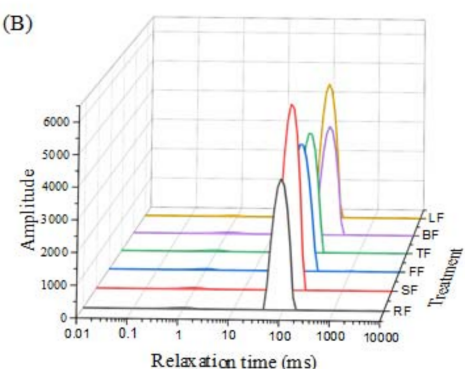

$3 \mathrm{~d}$

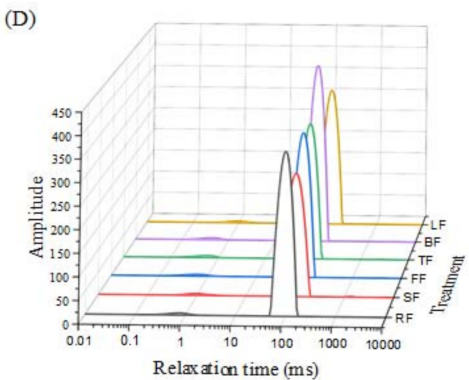

$60 \mathrm{~d}$

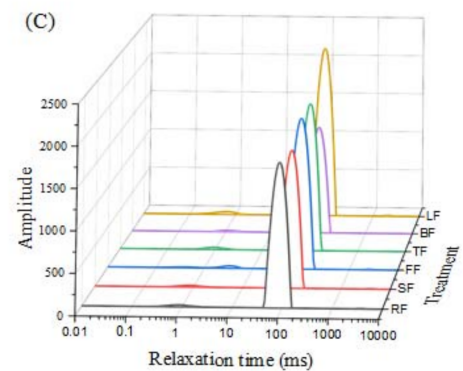

$30 \mathrm{~d}$

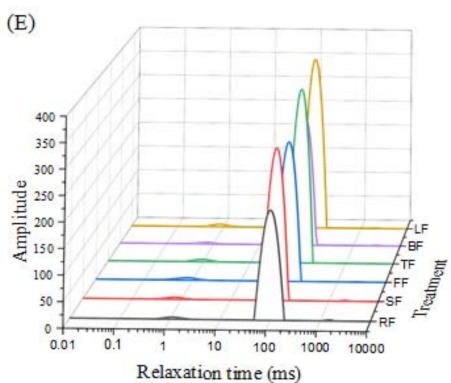

$90 \mathrm{~d}$

(F)

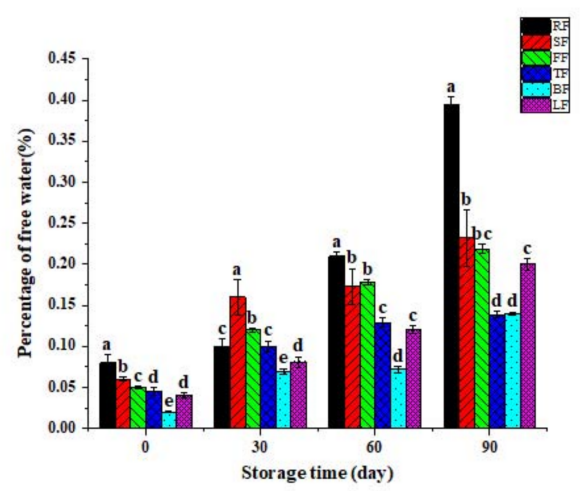

Figure 3. LF-NMR $T_{2}$ relaxation time distribution curves for cuttlefish with different treatment conditions (A-E represent the samples stored for fresh, $3 \mathrm{~d}, 30 \mathrm{~d}, 60 \mathrm{~d}, 90 \mathrm{~d}$, respectively). Change in percentage of free of cuttlefish during storage at $-18{ }^{\circ} \mathrm{C}$ by different freezing methods $(\mathbf{F})$. The letters

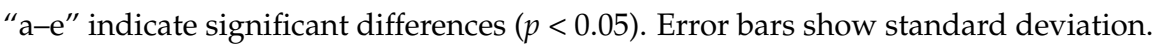




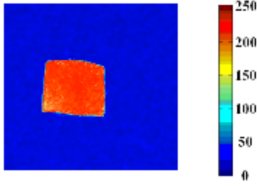

Fresh
RF
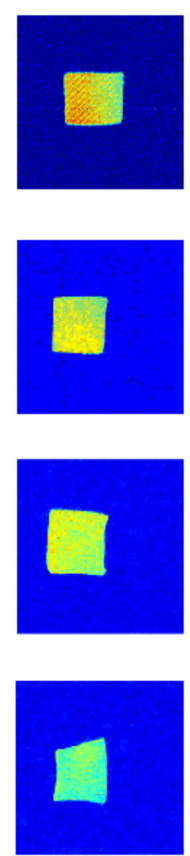

SF
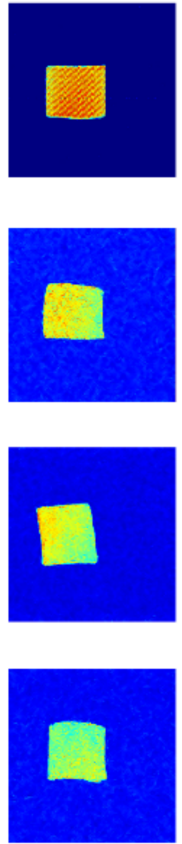

FF
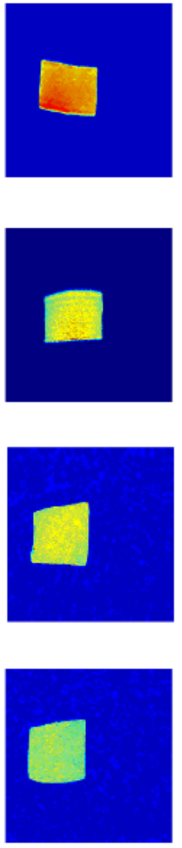

TF
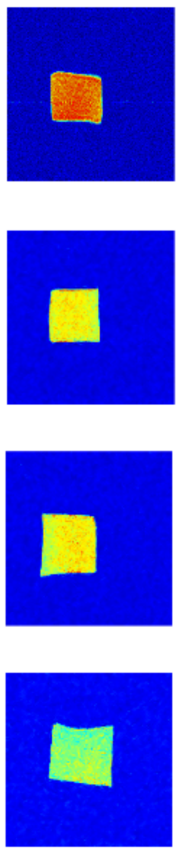

BF
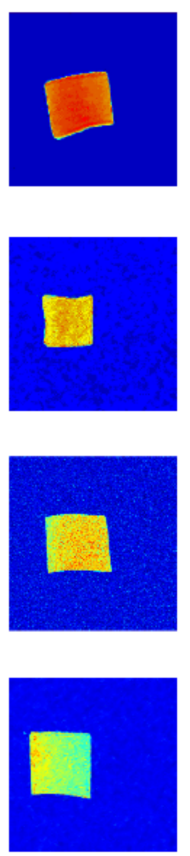

$\mathbf{L F}$
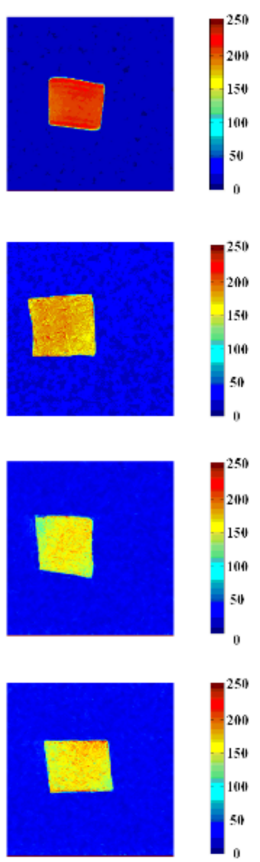

Figure 4. Magnetic resonance imaging (MRI) of cuttlefish by different freezing methods during frozen storage at $-18^{\circ} \mathrm{C}$.

\subsection{Total Sulfhydryl Content (T-SH)}

Sulfhydryl groups in protein structure are the most reactive of all protein amino acid residues. During freezing of cuttlefish, the generation of ice crystals increases intercellular osmotic pressure, protein molecules in tissues are denatured by salting or heavy metal action, and sulfhydryl groups are exposed to oxidation to disulfide bonds, causing a decrease in content and a concomitant increase in disulfide bonds [24]. Thus total sulfhydryl content is an important indicator of the degree of protein oxidation. The lower the total sulfhydryl content, the higher the degree of protein oxidation and the lower the quality of small yellow croaker. The changes in T-SH content of cuttlefish during storage at $-18^{\circ} \mathrm{C}$ under different freezing methods is shown in Figure 5. The sulfhydryl content of fresh cuttlefish was $0.61 \mathrm{mmol} / \mathrm{g}$ prot. During the storage period of 90 days, the active sulfhydryl content decreased with the extension of freezing time, with a relatively rapid decrease in the RF group. On the 90th day of storage, the total sulfhydryl content of small yellow croaker from liquid nitrogen freezing was $0.37 \mathrm{mmol} / \mathrm{g}$ prot, which was significantly higher than the other five groups $(p<0.05)$, indicating that liquid nitrogen freezing could effectively reduce the denaturation of muscle fibrous proteins in small yellow croaker meat. This was followed by the BF group with a total sulfhydryl content of $0.26 \mathrm{mmol} / \mathrm{g}$ prot and the RF group with the lowest total sulfhydryl content of $0.11 \mathrm{mmol} / \mathrm{g}$ prot. 


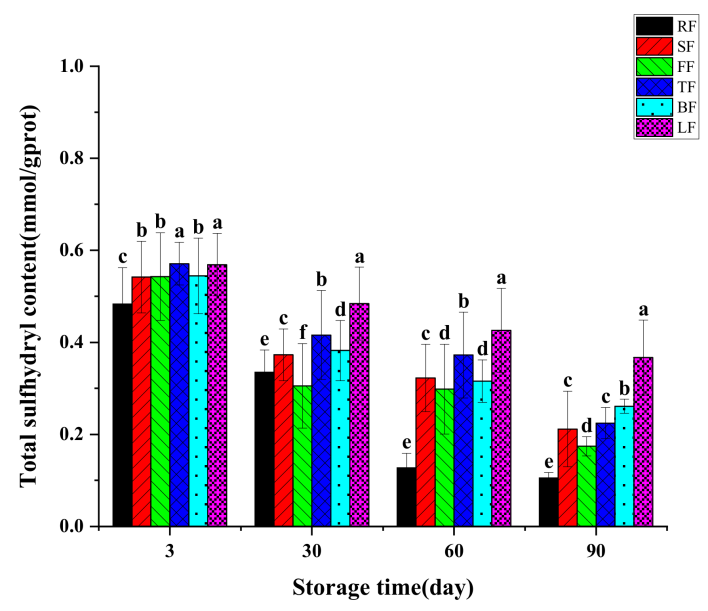

Figure 5. Change in T-SH content of cuttlefish during storage at $-18^{\circ} \mathrm{C}$ by different freezing methods. The letters " $\mathrm{a}-\mathrm{f}$ " indicate significant differences $(p<0.05)$. Error bars show standard deviation.

\section{6. $T V B-N$}

Total volatile basic nitrogen (TVB-N) refers to substances such as ammonia and amines produced by the decomposition of protein in animal foods due to the effects of various enzymes and microorganisms, which is an important indicator of meat spoilage [25]. The higher the TVB-N value, the lower the freshness of the meat and the higher the level of spoilage. The TVB-N content of fresh cuttlefish meat was $6.11 \mathrm{mg} \mathrm{N} / 100 \mathrm{~g}$ as shown in Figure 6, and the TVB-N values all showed an increasing trend with the extension of freezing time. The TVB-N values of liquid nitrogen freezing and air-blast freezing were $8.33 \mathrm{mg} \mathrm{N} / 100 \mathrm{~g}$ and $8.26 \mathrm{mgN} / 100 \mathrm{~g}$, respectively, after 90 day of freezing. There was no significant difference $(p>0.05)$. The highest TVB-N content was found in the flat freezing group, which was consistent with the water-holding capacity and sensory evaluation. The flat freezing group destroyed the muscle tissue of cuttlefish, and the excessive extrusion during the freezing process made its internal organs broken and accelerated the deterioration of its quality. Compared with other freezing methods, liquid nitrogen freezing and air-blast freezing may prevent denaturation of myosin heavy chains and better maintain the freshness of cuttlefish by reducing the mechanical damage of ice crystals to proteins.

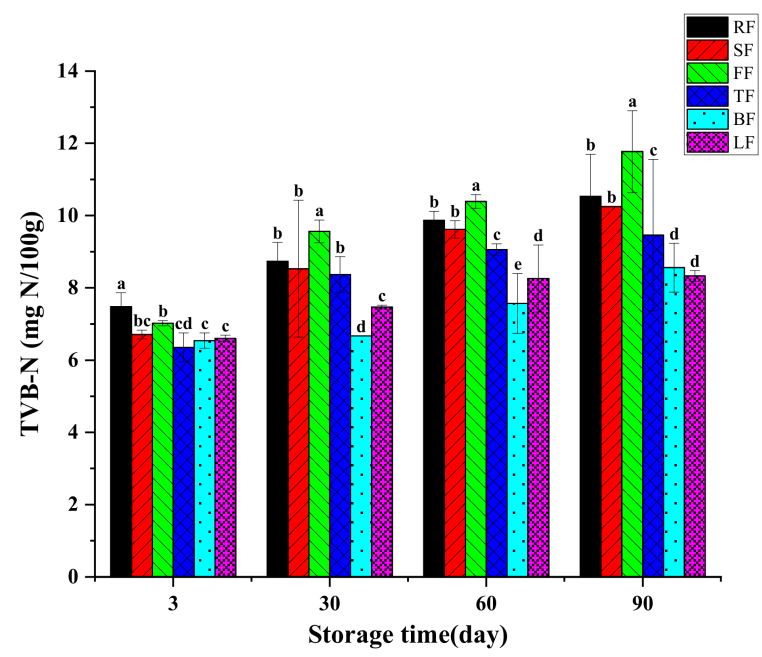

Figure 6. Change in TVB-N content of cuttlefish during storage at $-18{ }^{\circ} \mathrm{C}$ by different freezing methods. The letters "a-e" indicate significant differences $(p<0.05)$. Error bars show standard deviation. 


\subsection{ATR-FTIR}

The absorption peaks in the $1600-1700 \mathrm{~cm}^{-1}$ band caused by the stretching vibrations of $\mathrm{C}=\mathrm{O}$ are called amide I bands, and these characteristic absorption peaks are mainly caused by vibrations of the secondary structures of peptides and proteins. For the amide I band second derivative and deconvolution techniques were used for peak splitting, and the secondary structure of the protein was quantified by curve fitting. Figure 7 showed the IR spectra of cuttlefish by different freezing methods during frozen storage. Figure 8 shows the relative content of MP secondary structure of cuttlefish treated with different freezing methods during freezing. The protein secondary structures in cuttlefish flesh were mainly $\alpha$-helix $\left(1650-1660 \mathrm{~cm}^{-1}\right), \beta$-fold $\left(1660-1700 \mathrm{~cm}^{-1}\right), \beta$-fold $\left(1600-1640 \mathrm{~cm}^{-1}\right)$ and irregular convolution (1640-1650 $\mathrm{cm}^{-1}$ ). Figure $8 \mathrm{~A}, 8 \mathrm{D}$ show the contents of secondary structures of cuttlefish at 3 and 90 days of freezing storage, respectively. The comparison revealed that the $\alpha$-helix content of cuttlefish myofibrillar protein decreased significantly after 90 days of freezing storage, while the irregular curl content increased significantly, and the trends of $\beta$-fold and $\beta$-flip angles did not show a clear pattern. On the 90th day of storage, the FF group had the least $\alpha$-helix content, which decreased by $56.20 \%$ compared with the 3rd day, and the corresponding irregular curl content was the highest, which increased by $52.70 \%$ compared with its 3rd day. $\alpha$-helix content of TF, BF and LF groups were not significantly different $(p<0.05)$, and the LF group had the least irregular curl content. This is consistent with the previous results of microstructure under electron microscopy. The decrease of $\alpha$-helix indicates that the hydrolysis, oxidation and interaction of cuttlefish protein during frozen storage exposed the original hydrophobic groups in the molecule and increased the hydrophobicity of the protein surface, thus affecting the protein structure. At the same time, frozen storage resulted in an aggregation of proteins and disruption of intermolecular hydrogen bonds, which transformed the secondary structure into an irregular one.

(A)

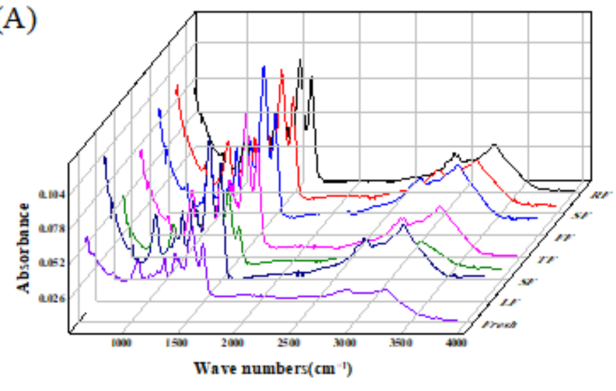

$3 d$

(C)

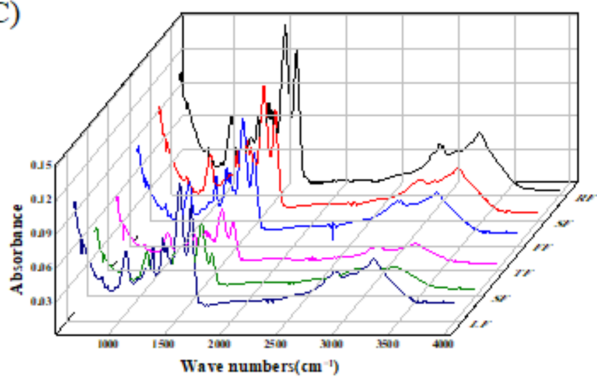

$60 \mathrm{~d}$

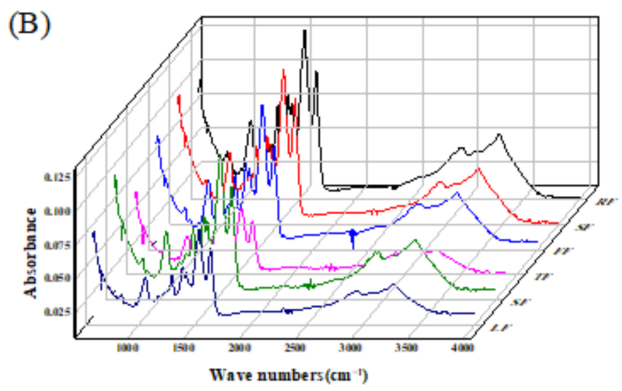

(B)

30d

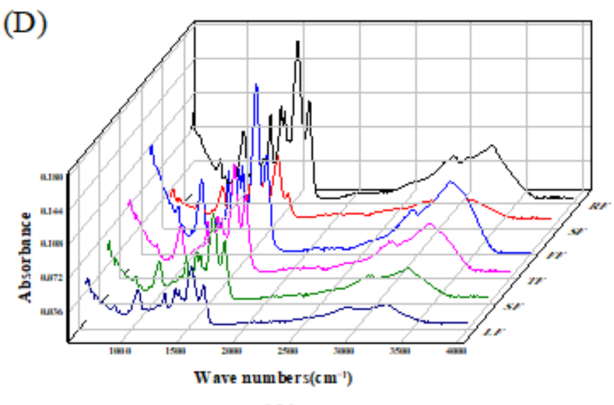

90d

Figure 7. ATR-FTIR spectra of cuttlefish with different freezing methods during freezing at $-18{ }^{\circ} \mathrm{C}$. (A-D, represent the samples stored for $3 \mathrm{~d}, 30 \mathrm{~d}, 60 \mathrm{~d}, 90 \mathrm{~d}$, respectively). 
(A)

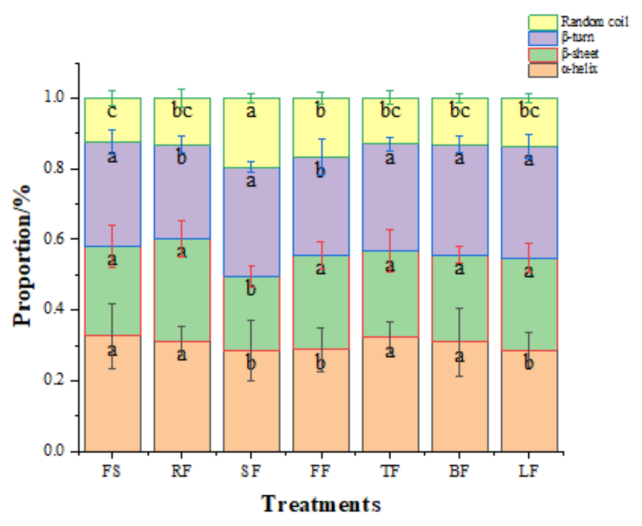

3d

(C)

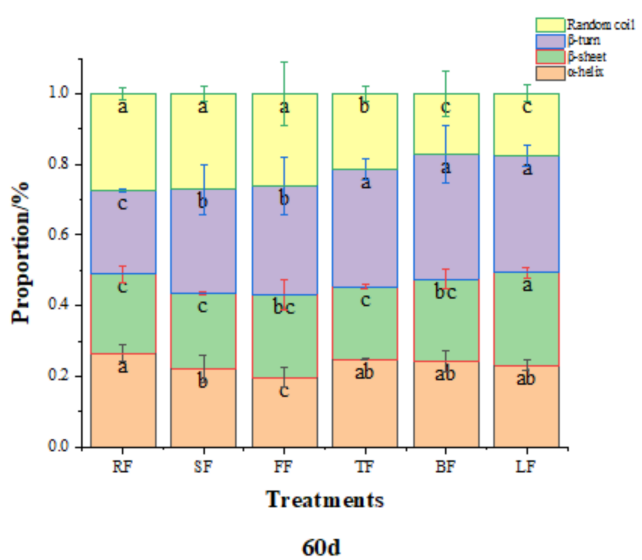

(B)

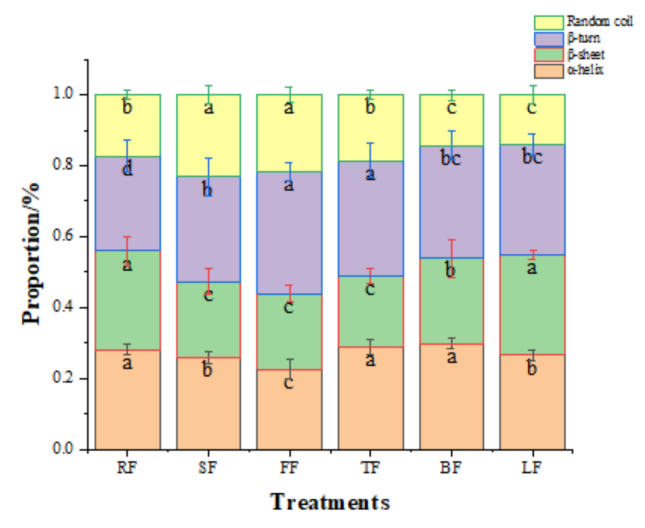

30d

(D)

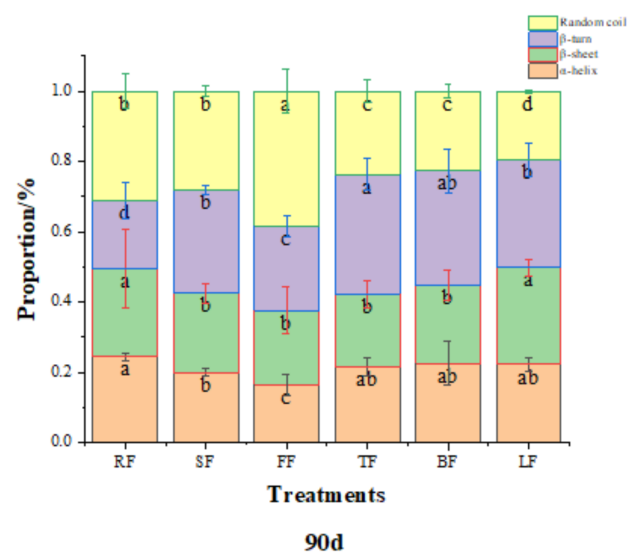

Figure 8. Change in secondary strucure content of cuttlefish during storage at $-18^{\circ} \mathrm{C}$ by different freezing methods. Different the superscript letters $(\mathrm{a}-\mathrm{d})$ indicates a significant difference between treatment and control at $p \leq 0.05$. (A-D, represent the samples stored for $3 \mathrm{~d}, 30 \mathrm{~d}, 60 \mathrm{~d}, 90 \mathrm{~d}$, respectively; FS represents fresh cuttlefish).

\subsection{Microscopic Observation}

Cuttlefish is an organism with high moisture content. The large size and distribution of ice crystals generated during the freezing process of cuttlefish can be indirectly reflected by the gap size and distribution of muscle fiber bundles, and the cross-section of cuttlefish muscle fibers during freezing was observed by scanning electron microscopy. As shown in Figure 9, the fresh cuttlefish had intact and densely arranged neat tissues with no obvious gaps. After treatment with six different freezing methods, there were more obvious interstices and cavities between tissues, which were spaces left by sublimation of ice crystals [26]. It was clearly seen that freezer freezing and brine dipping freezing generated larger and irregularly sized ice crystals, the fish was squeezed and muscle fibers appeared broken in flat freezing, tunnel continuous. The ice crystals generated by continuous tunnel freezing and air-blast freezing were smaller, more regular in size and with a clearer fiber structure, and the cuttlefish frozen in liquid nitrogen formed a large number of fine ice crystals with a uniform distribution. It has been found that the main fillers in the interstitial spaces of myogenic fibers are sarcoplasmic proteins and myosin, etc. [27]. Among them, sarcoplasmic protein content is high and water soluble, with the extension of freezing time, ice crystals within fish tissue grow further, water loss intensifies after thawing, sarcoplasmic protein leaching increases, and myogenic fiber voids increase [28], while the myogenic fibers themselves undergo freezing denaturation, contributing to the degradation of myogenic fibrillar proteins and increased fragmentation. On the 90th day of storage, the RF group samples showed large cell gaps and obvious 
traces of ice crystal destruction, while the SF and FF groups showed collapsed tissues and twisted and deformed myogenic fibers. The LF group had more intact cells, but the traces of ice crystal enlargement were also obvious. The BF group also all showed large gaps, but the structure was still relatively regular. The results indicate that different freezing methods have very different effects on cuttlefish muscle tissue, and liquid nitrogen flash freezing can slow down the deterioration of cuttlefish microstructure, probably because the fine regular ice crystals generated by liquid nitrogen flash freezing can protect the cell structure to some extent [29], which is consistent with what was previously.

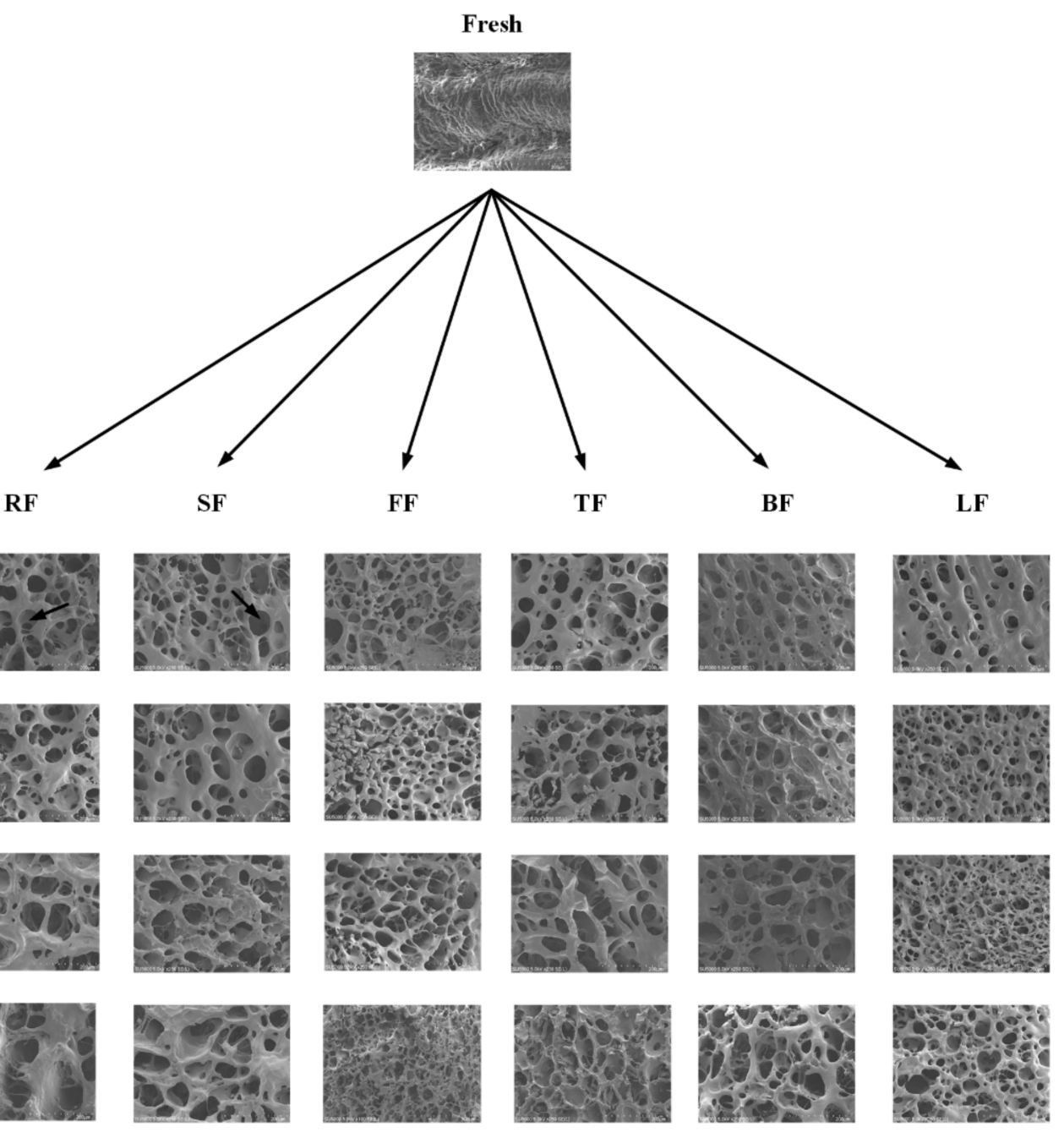

Figure 9. Scanning electron micrographs of cuttlefish during storage at $-18{ }^{\circ} \mathrm{C}$ by different freezing methods.

\section{9. $M D A$}

The content of MDA in fresh cuttlefish muscle is $0.05 \mathrm{mg} / \mathrm{kg}$. Freezing process of aquatic products due to the role of ice crystals will damage the original cell membrane structure of aquatic products, resulting in the release of non-heme iron ions in the cell, oxidase, superoxide radicals into hydroxyl radicals, further promote the oxidation of fat, get degradation products aldehyde, ketone, etc., so the greater the degree of fat oxidation, the higher the content of malondialdehyde generated [5]. Figure 10 showed the changes of MDA content of cuttlefish during freezing in different freezing methods, and it can be seen that the MDA values of cuttlefish basically showed a significant increasing trend during freezing, with the RF group rising most rapidly and the BF group rising slowly, and the content of MDA measured at 3, 30,60 and 90 days was the lowest among the six groups. Although the liquid nitrogen freezing group had the fastest freezing rate, although the 
damage of ice crystals to muscle tissue was reduced, the phenomenon of low-temperature fracture occurred locally in the cuttlefish after freezing, and to some extent muscle tissue and cell tissue were still damaged, so the oxidation of fat after 90 days of storage was greater than that in the TF and BF groups. The maximum values of MDA in all groups during the whole freezing process did not exceed $0.22 \mathrm{mg} \mathrm{MDA} / \mathrm{kg}$, indicating that the fat in cuttlefish during the whole freezing cycle did not reach a serious state of acidification.

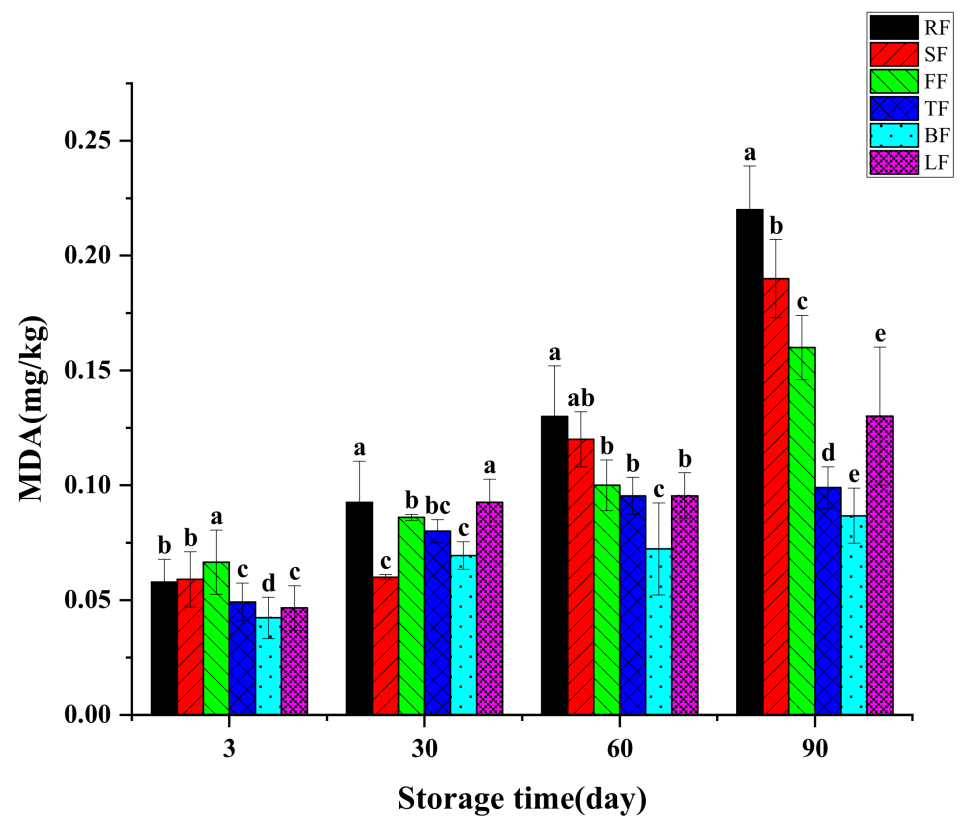

Figure 10. Change in MDA content of cuttlefish during storage at $-18^{\circ} \mathrm{C}$ by different freezing methods. The letters "a-e" indicate significant differences $(p<0.05)$. Error bars show standard deviation.

\subsection{Sensory Evaluation}

It is generally believed that the faster the freezing rate, the shorter the time for the product to pass through the maximum ice crystal generation zone, and the less the damage of ice crystals to muscle tissue, the better the quality of the samples can be maintained during long-term storage, and the samples will be closer to the fresh state after thawing. However, some studies had found that the effect of freezing rate on the quality of river crabs was better when the freezing rate was faster, but the super-low temperature freezing can also lead to muscle tearing of some products. The changes in sensory scores of cuttlefish meat during storage for different freezing methods was shown in Figure 11. Fresh cuttlefish had a pleasant distinctive fresh taste, creamy white flesh color, and intact morphology without damage. Nurkhoeriyati et al. [30] found that denaturation and coagulation of myogenic fibrous proteins occurred during freezing, leading to changes in functional properties of the muscle, while fat oxidation affected the odor and color of the meat, thus reducing the sensory quality of the fish meat [31]. In this experiment, on the 3rd day of freezing, the odor of the six groups of samples was similar, while the color and morphology had started to differ, and the morphology of the flat frozen cuttlefish was damaged due to the extrusion received from external forces, and the muscle of cuttlefish appeared uneven and sunken. Because of the fast freezing rate of liquid nitrogen and the small size of the ice crystals formed, it was still better than the other groups in terms of color and odor. However, the freezing rate of liquid nitrogen freezing is fast, and there will be temperature difference between the surface and the center of cuttlefish. Because of the thicker and larger size of cuttlefish, high water content, and high expansion pressure of freezing, local cracking phenomenon will occur during the freezing process, and the integrity of morphology will be destroyed. At the end of storage, the freshness of each group of cuttlefish disappeared and a less friendly odor appeared, and the color of the muscles of each group began to turn yellow, among which the local muscles of RF and FF groups showed browning. With the 
extension of the storage period, the sensory scores of all groups became significantly worse.

Overall, the BF group performed the best.

(A)

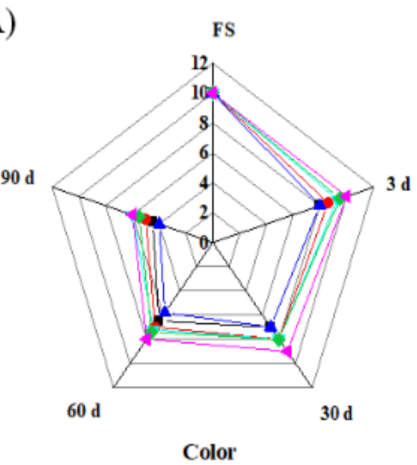

(B)

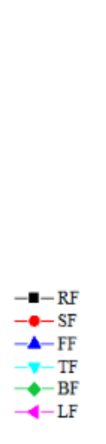

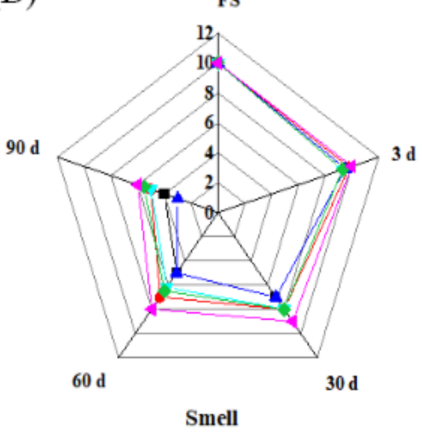

(C)

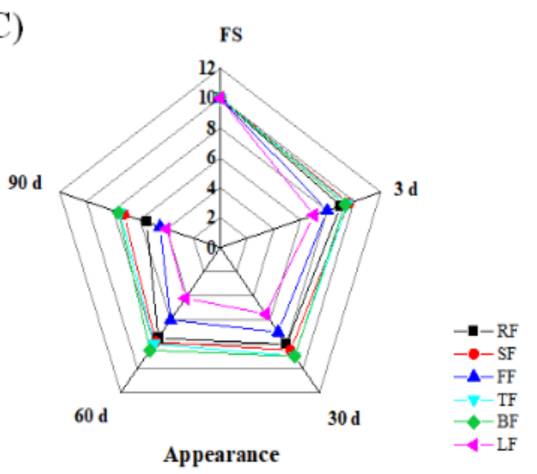

Figure 11. Change in color (A), smell (B), appearance (C) of cuttlefish during storage at $-18{ }^{\circ} \mathrm{C}$ by different freezing methods (FS represents fresh cuttlefish).

\section{Conclusions}

During freezing and storage, overall, liquid nitrogen freezing showed lower changes in all indicators than the other groups. At the 90th day of storage, the liquid nitrogen freezing group performed better than the other five groups in terms of water retention, microstructure, protein oxidation, and fat oxidation, which proved that liquid nitrogen freezing was still superior to other freezing methods in maintaining the quality of cuttlefish, but liquid nitrogen freezing caused low-temperature fractures and cracks in the external muscles due to its too-low freezing temperature, which adversely affected the appearance of cuttlefish morphology and consumer purchase. $\mathrm{CaCl}_{2}$ impregnation freezing requires an airtight and unbreakable package, otherwise the freezing liquid will contaminate the cuttlefish. Air-blast freezing has higher freezing rate and the performance of each quality is second only to liquid nitrogen freezing, which can maintain the quality of cuttlefish better.

Author Contributions: Conceptualization, Y.L. and J.X.; methodology, Y.L.; software, Y.L.; validation, Y.L.; formal analysis, Y.L.; investigation, Y.L., Y.C. and P.Z.; resources, J.X.; data curation, Y.L.; writing-original draft preparation, Y.L.; writing—review and editing, J.X. and J.M.; visualization, Y.L.; supervision, J.X.; project administration, J.X.; funding acquisition, J.X. All authors have read and agreed to the published version of the manuscript.

Funding: This research was financially supported by the National Key R\&D Program of China (2019YFD0901604), the Key Project of Science and Technology Commission of Shanghai Municipality (19DZ1207503), and the Shanghai Professional Technology Service Platform on Cold Chain Equipment Performance and Energy Saving Evaluation (19DZ2284000).

Institutional Review Board Statement: Not applicable.

Informed Consent Statement: Not applicable.

Data Availability Statement: Not applicable.

Conflicts of Interest: The authors declare no conflict of interest.

\section{References}

1. Mozuraityte, R.; Standal, I.B.; Cropotova, J.; Budźko, E.; Rustad, T. Superchilled, chilled and frozen storage of Atlantic mackerel (Scomber scombrus) -Effect on lipids and low molecular weight metabolites. Int. J. Food Sci. Technol. 2020, 56, 1918-1928. [CrossRef]

2. Sun, Q.; Sun, F.; Xia, X.; Xu, H.; Kong, B. The comparison of ultrasound-assisted immersion freezing, air freezing and immersion freezing on the muscle quality and physicochemical properties of common carp (Cyprinus carpio) during freezing storage. Ultrason. Sonochem. 2019, 51, 281-291. [CrossRef]

3. Nakazawa, N.; Wada, R.; Fukushima, H.; Tanaka, R.; Kono, S.; Okazaki, E. Effect of long-term storage, ultra-low temperature, and freshness on the quality characteristics of frozen tuna meat. Int. J. Refrig. 2020, 112, 270-280. [CrossRef] 
4. Martinez, I.; Bathen, T.; Standal, I.B.; Halvorsen, J.; Aursand, M.; Gribbestad, I.S.; Axelson, D.E. Bioactive Compounds in Cod (Gadus morhua) Products and Suitability of1H NMR Metabolite Profiling for Classification of the Products Using Multivariate Data Analyses. J. Agric. Food Chem. 2005, 53, 6889-6895. [CrossRef] [PubMed]

5. Boonsumrej, S.; Chaiwanichsiri, S.; Tantratian, S.; Suzuki, T.; Takai, R. Effects of freezing and thawing on the quality changes of tiger shrimp (Penaeus monodon) frozen by air-blast and cryogenic freezing. J. Food Eng. 2007, 80, 292-299. [CrossRef]

6. Gonçalves, A.A.; Ribeiro, J.L.D. Optimization of the freezing process of red shrimp (Pleoticus muelleri) previously treated with phosphates. Int. J. Refrig. 2008, 31, 1134-1144. [CrossRef]

7. Cohen-Zinder, M.; Orlov, A.; Trofimyuk, O.; Agmon, R.; Kabiya, R.; Shor-Shimoni, E.; Wagner, E.K.; Hussey, K.; Leibovich, H.; Miron, J.; et al. Dietary supplementation of Moringa oleifera silage increases meat tenderness of Assaf lambs. Small Rumin. Res. 2017, 151, 110-116. [CrossRef]

8. Li, X.-X.; Sun, P.; Jia, J.-Z.; Cai, L.-Y.; Li, J.-R.; Lv, Y.-F.; Li, X.-X.; Sun, P.; Jia, J.-Z.; Cai, L.-Y.; et al. Effect of low frequency ultrasound thawing method on the quality characteristics of Peru squid (Dosidicus gigas). Food Sci. Technol. Int. 2018, 25, 171-181. [CrossRef]

9. Tan, M.; Ye, J.; Chu, Y.; Xie, J. The effects of ice crystal on water properties and protein stability of large yellow croaker (Pseudosciaena crocea). Int. J. Refrig. 2021. [CrossRef]

10. Wang, J.; Yu, W.; Xie, J. Effect of Glazing with Different Materials on the Quality of Tuna During Frozen Storage. Foods 2020, 9, 231. [CrossRef]

11. Syamaladevi, R.; Manahiloh, K.; Muhunthan, B.; Sablani, S.S. Understanding the Influence of State/Phase Transitions on Ice Recrystallization in Atlantic Salmon (Salmo salar) During Frozen Storage. Food Biophys. 2011, 7, 57-71. [CrossRef]

12. Li, P.; Mei, J.; Xie, J. Chitosan-sodium alginate bioactive coatings containing $\varepsilon$-polylysine combined with high $\mathrm{CO}_{2}$ modified atmosphere packaging inhibit myofibril oxidation and degradation of farmed pufferfish (Takifugu obscurus) during cold storage. LWT 2021, 140, 110652. [CrossRef]

13. Yu, D.; Regenstein, J.M.; Zang, J.; Jiang, Q.; Xia, W.; Xu, Y. Inhibition of microbial spoilage of grass carp (Ctenopharyngodon idellus) fillets with a chitosan-based coating during refrigerated storage. Int. J. Food Microbiol. 2018, 285, 61-68. [CrossRef] [PubMed]

14. Kobayashi, Y.; Mayer, S.G.; Park, J.W. FT-IR and Raman spectroscopies determine structural changes of tilapia fish protein isolate and surimi under different comminution conditions. Food Chem. 2017, 226, 156-164. [CrossRef]

15. Zhang, X.; Gao, T.; Song, L.; Zhang, L.; Jiang, Y.; Li, J.-L.; Gao, F.; Zhou, G.-H. Effects of different thawing methods on the quality of chicken breast. Int. J. Food Sci. Technol. 2017, 52, 2097-2105. [CrossRef]

16. Meral, R.; Alav, A.; Karakas, C.; Dertli, E.; Yilmaz, M.T.; Ceylan, Z. Effect of electrospun nisin and curcumin loaded nanomats on the microbial quality, hardness and sensory characteristics of rainbow trout fillet. LWT 2019, 113, 108292. [CrossRef]

17. Xu, Z.; Guo, Y.; Ding, S.; An, K.; Wang, Z. Freezing by immersion in liquid $\mathrm{CO}_{2}$ at variable pressure. Innov. Food Sci. Emerg. Technol. 2014, 22, 167-174. [CrossRef]

18. Zorzi, K.; Bonilha, S.; Queiroz, A.; Branco, R.; Sobrinho, T.; Duarte, M. Meat quality of young Nellore bulls with low and high residual feed intake. Meat Sci. 2013, 93, 593-599. [CrossRef] [PubMed]

19. Queiroga, I.M.B.N.; Silva, J.A.d.; Cavalheiro, J.M.O.; Queiroga, R.d.C.R.E.; Batista, A.S.M.; Barreto, T.A. Sensory quality of frozen shrimp Litopenaeus vannamei. Semin. Ciênc. Agrár. 2014, 35, 1801-1812. [CrossRef]

20. Duman, M.; Peksezer, B. Chemical and sensory quality changes in fish balls prepared from Alburnus mossulensis Heckel, 1843 during frozen storage. J. Appl. Ichthyol. 2016, 32, 559-563. [CrossRef]

21. Finch, E.D.; Harmon, J.; Muller, B.H. Pulsed NMR measurements of the diffusion constant of water in muscle. Arch. Biochem. Biophys. 1971, 147, 299-310. [CrossRef]

22. Sánchez-Alonso, I.; Martinez, I.; Sánchez-Valencia, J.; Careche, M. Estimation of freezing storage time and quality changes in hake (Merluccius merluccius, L.) by low field NMR. Food Chem. 2012, 135, 1626-1634. [CrossRef] [PubMed]

23. Tan, M.; Xie, J. Exploring the Effect of Dehydration on Water Migrating Property and Protein Changes of Large Yellow Croaker (Pseudosciaena crocea) during Frozen Storage. Foods 2021, 10, 784. [CrossRef] [PubMed]

24. Feng, X.; Li, C.; Ullah, N.; Cao, J.; Lan, Y.; Ge, W.; Hackman, R.M.; Li, Z.; Chen, L. Susceptibility of whey protein isolate to oxidation and changes in physicochemical, structural, and digestibility characteristics. J. Dairy Sci. 2015, 98, 7602-7613. [CrossRef] [PubMed]

25. Huang, W.; Wang, J.; Song, H.; Zhang, Q.; Liu, G. Effect of Antimicrobial Packaging Film Coated with Ajowan and Cinnamon Essential Oil on Shelf Life of Fresh Chilled Pork. In Applied Sciences in Graphic Communication and Packaging; Springer: Berlin/Heidelberg, Germany, 2018; pp. 787-797. [CrossRef]

26. Ngapo, T.; Babare, I.; Reynolds, J.; Mawson, R. A preliminary investigation of the effects of frozen storage on samples of pork. Meat Sci. 1999, 53, 169-177. [CrossRef]

27. Lin, W.-L.; Zeng, Q.-X.; Zhu, Z.-W. Different changes in mastication between crisp grass carp (Ctenopharyngodon idellus C.et V) and grass carp (Ctenopharyngodon idellus) after heating: The relationship between texture and ultrastructure in muscle tissue. Food Res. Int. 2009, 42, 271-278. [CrossRef]

28. Bremner, H.A.; Hallett, I.C. Muscle Fiber-Connective Tissue Junctions in the Fish Blue Grenadier (Macruronus novaezelandiae). A Scanning Electron Microscope Study. J. Food Sci. 2010, 50, 975-980. [CrossRef]

29. Kaale, L.D.; Eikevik, T.M. Changes of proteins during superchilled storage of Atlantic salmon muscle (Salmo salar). J. Food Sci. Technol. 2015, 53, 441-450. [CrossRef] 
30. Nurkhoeriyati, T.; Huda, N.; Ahmad, R. Physicochemical Properties and Sensory Analysis of Duck Meatballs Containing Duck Meat Surimi-Like Material during Frozen Storage. J. Food Sci. 2012, 77, S91-S98. [CrossRef]

31. Ruiz-Capillas, C.; Moral, A. Sensory and biochemical aspects of quality of whole bigeye tuna (Thunnus obesus) during bulk storage in controlled atmospheres. Food Chem. 2005, 89, 347-354. [CrossRef] 